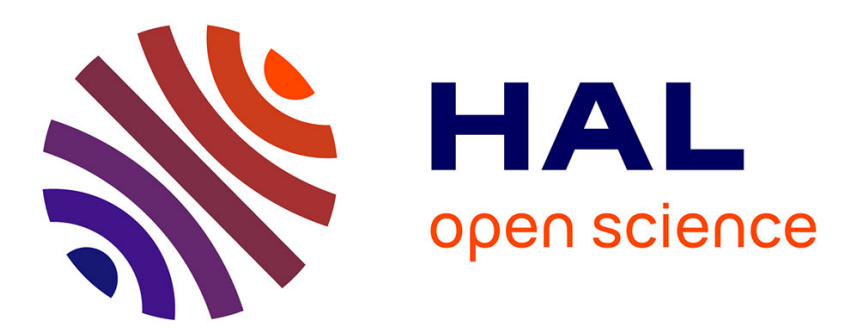

\title{
A binary gas transport model Improves the prediction of mass transfer in freeze drying
}

Ioan-Cristian Trelea, Fernanda Fonseca, Stéphanie Passot, Denis Flick

\section{To cite this version:}

Ioan-Cristian Trelea, Fernanda Fonseca, Stéphanie Passot, Denis Flick. A binary gas transport model Improves the prediction of mass transfer in freeze drying. Drying Technology, 2015, 33 (15-16), pp.1849-1858. 10.1080/07373937.2015.1040025 . hal-01269386

\section{HAL Id: hal-01269386 \\ https://hal.science/hal-01269386}

Submitted on 11 Jul 2017

HAL is a multi-disciplinary open access archive for the deposit and dissemination of scientific research documents, whether they are published or not. The documents may come from teaching and research institutions in France or abroad, or from public or private research centers.
L'archive ouverte pluridisciplinaire HAL, est destinée au dépôt et à la diffusion de documents scientifiques de niveau recherche, publiés ou non, émanant des établissements d'enseignement et de recherche français ou étrangers, des laboratoires publics ou privés. 
Title:

\section{A binary gas transport model improves the prediction of mass transfer in freeze-drying}

Short title: Binary gas transport model in freeze-drying

Ioan Cristian Trelea ${ }^{1,2}$, Fernanda Fonseca ${ }^{2,1}$, Stéphanie Passot $^{1,2}$, Denis Flick ${ }^{3,4}$ ${ }^{1}$ AgroParisTech, UMR782 Génie et Microbiologie des Procédés Alimentaires, 1 av. Lucien Brétignières, F-78850 Thiverval-Grignon, France ${ }^{2}$ INRA, UMR782 Génie et Microbiologie des Procédés Alimentaires, 1 av. Lucien Brétignières, F-78850 Thiverval-Grignon, France ${ }^{3}$ AgroParisTech UMR1145 Ingénierie Procédés Aliments 1 av. des Olympiades, F-91300 Massy, France ${ }^{4}$ INRA, UMR1145 Ingénierie Procédés Aliments 1 av. des Olympiades, F-91300 Massy, France

*Corresponding author: Tel.:+331308154 90, E-mail: cristian.trelea@agroparistech.fr

$\underline{\text { Abstract }}$

Monitoring partial vapor pressure in the freeze-drying chamber is a cheap, global and non-intrusive way to assess the end of the primary drying stage. Most existing dynamic freeze-drying models which predict this partial pressure describe mass transfer between the product and the condenser via a mass transfer resistance or a mass transfer coefficient. Experimental evidence suggests that such models can be significantly in error for some 
values of the sublimation flux, leading to physically inconsistent predictions and possibly incorrect assessment of primary drying termination, with potential risk of product damage if moving to secondary drying and increasing shelf temperature while some ice is still present. Assuming a binary gas transport model for vapor and inert gas leads to improved and consistent predictions and explains the apparent variation of the mass transfer resistance with total pressure, shelf temperature and product sublimation area.

Keywords: lyophilization, dynamic model, mass transfer, convection, diffusion (1) (1)

\section{INTRODUCTION}

Freeze-drying (lyophilization) is widely used for long term preservation of thermosensitive biological material and pharmaceuticals, such as proteins, vaccines, bacteria, mammalian cells and high quality food. ${ }^{[1,2]}$ It removes water or an organic solvent in a way that minimizes the modification of the molecular structure of the active ingredient and creates a porous matrix with high rehydration properties. Freeze-drying remains a costly process, however, and lot of

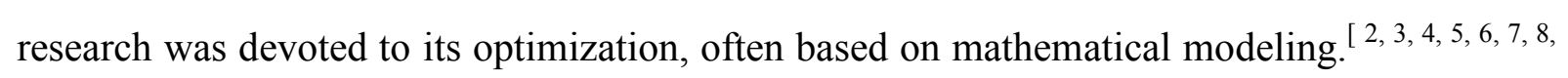
$9,10,11,12]$

The process consists of three main steps: freezing, ice removal by sublimation (primary drying) and unfrozen water removal by desorption from the solid matrix (secondary drying). The primary drying stage is usually the most time and energy consuming part of a freezedrying cycle. A lot of research has been devoted to the development of methods to precisely and consistently identify the end of the primary drying. Most of these methods rely on the monitoring of the vapor partial pressure in the freeze-drying chamber, either directly (moisture sensors such as aluminum oxide probes) and/or indirectly (Pirani gauge, mass spectrometer, Tunable Diode Laser Absorption Spectroscopy (TDLAS)). ${ }^{\left[13,{ }^{14}\right]}$ Moreover, abundant literature is available concerning modeling of primary freeze-drying for optimizing 
this step of the process off line and also more recently in real time. ${ }^{[11,12,15]}$ Models often predict the product temperature and the sublimation flux. The rate of solvent vapor removal from the product is usually described as being governed by three barriers or resistances: resistance of the dried-product layer, resistance of the containers (vials and stoppers), and resistance of the chamber to condenser pathway. Since the gas phase is mainly vapor during the primary drying and gradients of concentrations are small, true diffusion, or flow under the influence of a concentration gradient, is often considered of minor importance and models focus on bulk flow mechanisms. ${ }^{[16]}$ The resistance of the dried product layer and of the containers has been studied both theoretically and experimentally by many groups. These studies present two limitations, however. Firstly, the chamber resistance is usually neglected because of measurement difficulties, or it is estimated by rather complex approaches involving Computational Fluid Dynamics (CFD) simulations. ${ }^{[17,18,19,20]}$ Secondly, the partial vapor pressure is usually not predicted but taken as fixed and equal to the total chamber pressure, despite its importance for real time optimization and freeze-drying control. ${ }^{[3,10,21,22 \text {, }}$ 23, 24]

Our group previously developed a one-dimensional heat and mass transfer model, which can accurately represent both the primary and secondary drying stages and the gradual transition between them. ${ }^{[9]}$ When adapting it to other freeze-dryers and to bacterial suspensions, however, it turned out that the determined chamber resistance strongly varied with total pressure and shelf temperature. Moreover, for a sufficiently high sublimation flux, e.g. generated by a high shelf temperature at the beginning of the primary drying, the model can predict a partial vapor pressure higher than the total one, which is obviously incorrect.

In the present study the chamber resistance was experimentally determined and a model of mass transfer between the freeze-drying chamber and the condenser is proposed for the solvent vapor and inert gas pair. The model is based on the mass transfer theory in binary gas mixtures and includes bulk flow and mutual diffusion terms. This model improved the prediction of the chamber vapor pressure and of the primary drying termination. It also accounted for apparent variations of the effective mass transfer resistance with total pressure, shelf temperature and product sublimation area. 
Determination of the mass transfer resistance (vapor flow) of the chamber to condenser pathway

Experiments were carried out on a LyoBeta special freeze-dryer (Telstar, Terrassa, Spain) equipped with 5 thermocouples, a capacitive manometer and a Pirani gauge. Purified water and bacterial cell suspensions were successively considered.

A stainless steel tray was filled with purified water to a thickness of $3 \mathrm{~cm}$. The evaporative flow was determined using the gravimetric method. After freezing the water at $-50^{\circ} \mathrm{C}$ (cooling rate of $0.6{ }^{\circ} \mathrm{C} / \mathrm{min}$ ), and sublimation time between 4 and 8 hours depending on the experimental conditions, the process was stopped and the tray was weighted to determine the amount of water removed and thus the evaporative flux $\left(F_{V}\right.$, in $\left.\mathrm{kg} \mathrm{s}^{-1}\right)$. The mass transfer coefficient $\left(k_{m}, \mathrm{~kg} \mathrm{~s}^{-1} \mathrm{~Pa}^{-1}\right)$, or, equivalently, resistance of the chamber to condenser pathway $\left(r_{m}, \mathrm{~Pa} \mathrm{~s} \mathrm{~kg}^{-1}\right)$ was determined from Eq. 1:

100

Eq. 1

$$
F_{V}=k_{m}\left(P_{V 1}-P_{V 2}\right)=\frac{P_{V 1}-P_{V 2}}{r_{m}}
$$

101 with $P_{V 1}$, the water vapor partial pressure just above the product $(\mathrm{Pa})$, estimated from the ice 102 temperature and $P_{V 2}$, the water vapor partial pressure at the condenser $(\mathrm{Pa})$, estimated from 103 the condenser temperature.

104 The effect of three process variables on the effective mass resistance $\left(r_{m}\right)$ value was 105 investigated: sublimation area $\left(0.033,0.074\right.$ and $\left.0.15 \mathrm{~m}^{2}\right)$, chamber pressure $(10,20,40$ and $10660 \mathrm{~Pa})$ and shelf temperature $\left(-15,0\right.$ and $\left.15^{\circ} \mathrm{C}\right)$.

Freeze-drying experiments with bacterial suspensions

108 Lactic acid bacteria were produced by fermentation in controlled conditions of $\mathrm{pH}$ and 109 temperature. $^{[25]}$ After concentration, the bacterial cells were re-suspended in a 1:2 110 cells/protective medium ratio. The protective medium was composed of $200 \mathrm{~g} / \mathrm{L}$ of sucrose 111 and $0.15 \mathrm{M}$ of $\mathrm{NaCl}$. A stainless steel tray was filled with $450 \mathrm{~g}$ of bacterial suspension and 112 the following freeze-drying protocol was applied: freezing at $-50^{\circ} \mathrm{C}$ (cooling rate of $1130.6^{\circ} \mathrm{C} / \mathrm{min}$ ); primary drying at $-20,0$ or $25^{\circ} \mathrm{C}$; secondary drying at $25^{\circ} \mathrm{C}$ for 8 hours. The total 114 chamber pressure was controlled at either 20 or $60 \mathrm{~Pa}$. Thermocouples were placed at the 115 bottom of the product in the centre of the tray. 
117 The reading of a Pirani gauge in a pure gas is proportional to the pressure of the gas and to the 118 molecular heat conductivity of the gas. ${ }^{[26]}$ The main gases present in the freeze-drying 119 chamber are solvent vapor (usually water) and an inert gas such as nitrogen or air. Let

120 Eq. 2

$$
\alpha=\frac{\lambda_{V}}{\lambda_{N}}
$$

121 be the ratio of the molecular heat conductivities. This ratio is equal to 1.6 for the water vapor 122 and nitrogen pair. If the Pirani gauge is calibrated with inert gas, nitrogen in the present case,

123 then the reading in pure solvent vapor will be:

124 Eq. 3

$$
P_{V}^{P}=\alpha P_{V}
$$

125 In a gas mixture, the Pirani gauge will measure the sum of heat fluxes due to conduction in 126 each gas. The reading will be:

127 Eq. 4

$$
P^{P}=\alpha P_{V}+P_{N}
$$

128 In contrast, the capacitive sensor will give the true total pressure:

129 Eq. 5

$$
P_{t}=P_{V}+P_{N}
$$

130 From these two readings, one can determine the partial pressures of vapor and inert gas:

131 Eq. 6

$$
P_{V}=\frac{P^{P}-P_{t}}{\alpha-1}
$$

Eq. 7

$$
P_{N}=\frac{\alpha P_{t}-P^{P}}{\alpha-1}
$$

\section{Numeric calculations}

134 Calculations were performed with Matlab ${ }^{\text {TM }} 8$ software (The MathWorks Inc., Natick, MA)

135 equipped with the Statistics Toolbox and the Global Optimization Toolbox.

Mass transfer resistance model

138 In most previously developed freeze-drying models, the mass flux between the freeze-drying

139 chamber containing the product (location 1) and the condenser (location 2) was either 
140 ignored, considering the vapor pressure in the freeze-drying chamber as given, ${ }^{[3,10,21,22,23]}$ or 141 expressed via a mass transfer coefficient $\left(k_{m}\right)$ or, equivalently, via a mass transfer resistance $142\left(r_{m}\right),{ }^{[9,12,27,28,29]}$ as given by Eq. 1.

143 Note that in Eq. 1 the mass flux is proportional to the partial vapor pressure difference 144 between the two locations. Vapor pressure $P_{V 2}$ is usually fixed by the condenser temperature, 145 while the mass flux $F_{V}$ is mostly determined by the heat transfer flux from the temperature146 controlled shelf to the product, i.e. by the shelf temperature and the product sublimation area.

147 If the mass transfer resistance was constant, as it is usually assumed, then the partial vapor 148 pressure in the chamber $P_{V 1}$ would result from Eq. 1. If the mass flux was high enough, due 149 for example to high shelf temperature, a model based on Eq. 1 could even give a vapor 150 pressure higher that the total chamber pressure, which is obviously impossible. A more consistent mass transfer model is developed in the next section.

\section{Binary gas transport model}

153 Consider a mixture of two gases at low pressure; in the case of freeze-drying these gases 154 would be solvent vapor, usually water, released from the product and captured by the 155 condenser and the inert gas, usually nitrogen, used to control the total chamber pressure. To 156 determine the relevant mass transport theory, the Knudsen number, defined as the ratio of the 157 free mean path of the molecules and the characteristic dimension of the system, was 158 estimated. In the considered conditions, the free mean path is of order of $0.5 \mathrm{~mm}$ at $20 \mathrm{~Pa}$, 159 while the typical diameter of the chamber to condenser duct is $100 \mathrm{~mm}$. Knudsen diffusion can 160 thus be safely neglected for the chamber to condenser pathway considered here, since $161 K_{n} \approx 5 \times 10^{-3}$. Note that this is usually not the case in the porous product layer where the pore 162 size can be much less than $0.5 \mathrm{~mm}$, but mass transport in the porous layer is out of the scope 163 of the present study.

164 The classical theory of binary diffusion in gases states that the molar flux density of solvent 165 vapor, in stationary coordinates, is given by: ${ }^{[30]}$

166 Eq. 8

$$
N_{V}=x_{V}\left(N_{V}+N_{N}\right)-\left(c_{V}+c_{N}\right) D_{V N} \nabla x_{V}
$$

167 where $N_{V}$ and $N_{N}$ are molar flux densities, $c_{V}$ and $c_{N}$ molar concentrations of vapor and 168 nitrogen respectively, $x_{V}$ is the molar fraction of vapor and $D_{V N}$ is the mutual diffusion 169 coefficient. The first term on the right-hand side of Eq. 8 results from the bulk motion of the 170 fluid while the second one expresses the diffusion of vapor due to its molar fraction gradient. 
171 Assuming pseudo-stationary conditions, compared to the duration of a freeze-drying cycle 172 which is of one or several days, and assuming insignificant leaks in the freeze-drying 173 chamber, the net inert gas flux is negligible compared to the vapor flux:

174 Eq. 9

$$
N_{N} \approx 0
$$

175 Usual variables in freeze-drying are mass fluxes instead of molar fluxes and partial pressures

176 instead of molar fractions and concentrations. Using the ideal gas law one gets:

177 Eq. 10

$$
x_{V}=\frac{P_{V}}{P_{V}+P_{N}}=\frac{P_{V}}{P_{t}}
$$

$178 \quad$ Eq. 11

$$
c_{V}+c_{N}=\frac{P_{V}+P_{N}}{R T}=\frac{P_{t}}{R T}
$$

179 Eq. 12

$$
f_{V}=M_{V} N_{V}
$$

180 With these substitutions, and assuming that the variation of total pressure between freeze-

181 drying chamber and condenser is small compared to the variation in vapour partial pressure,

182 Eq. 8 becomes:

183 Eq. 13

$$
f_{V}\left(P_{t}-P_{V}\right)=-\frac{M_{V}}{R T} P_{t} D_{V N} \nabla P_{V}
$$

184 To solve Eq. 13, it is assumed that the vapour flux between the product and the condenser is 185 essentially one-dimensional. This assumption is relatively sound for freeze-driers equipped 186 with a condenser separated from the main freeze-drying chamber by a pipe, as is the case in 187 the present study, but it is questionable when the product and the condenser are situated in the 188 same cavity. With this assumption, Eq. 13 can be integrated between the freeze-drying chamber (location 1) and the condenser (location 2) giving:

190 Eq. 14

$$
F_{V}=A f_{V}=\frac{A M_{V}}{l_{\text {eff }} R T} P_{t} D_{V N} \ln \frac{P_{t}-P_{V 2}}{P_{t}-P_{V 1}}
$$

191 where $F_{V}$ is the vapor mass flux, while $A$ and $l_{\text {eff }}$ are the diffusion cross-section area and

192 effective duct length respectively. The effective length accounts for the presence of inlet and

193 outlet sections, bends, valve and other elements that can introduce additional resistances. 
194 The mutual gas diffusion coefficient $D_{V N}$ is inversely proportional to the total pressure, thus 195 the product $P_{t} D_{V N}$ is constant. ${ }^{[30]}$ For a given freeze-dryer geometry $\left(l_{\text {eff }}, A\right)$ a constant $\beta$ can 196 be introduced:

197 Eq. 15

$$
\beta=\frac{l_{e f f} R}{A M_{V} P_{t} D_{V N}}
$$

198 so that

199 Eq. 16

$$
F_{V}=\frac{1}{\beta T} \ln \frac{P_{t}-P_{V 2}}{P_{t}-P_{V 1}}
$$

The dependence of the mass flux on the partial vapor pressures given by Eq. 16 appears quite different from Eq. 1. It can be shown, however, using a first order Taylor series expansion of the logarithm function, that Eq. 1 is an approximation of Eq. 16 in the case when the vapor pressures are much less than the total pressure:

204 Eq. 17

$$
\ln \frac{P_{t}-P_{V 2}}{P_{t}-P_{V 1}} \approx \frac{P_{V 1}-P_{V 2}}{P_{t}} \quad \text { if } \quad P_{V 1} \ll<P_{t}
$$

It should be noted, however, than in freeze-drying the condition $P_{V 1}<<P_{t}$ is usually not satisfied as the gas in the freeze-drying chamber during primary drying is mostly solvent vapor. The approximation given by Eq. 17 is thus not expected to be valid. This can explain the mentioned inconsistency with Eq. 1 and the apparent variation of the effective mass transfer resistance with total pressure and mass flux, as further discussed below. For now, note that Eq. 16 can accommodate arbitrarily large vapor fluxes without $P_{V 1}$ exceeding $P_{t}$, provided that the difference $P_{t}-P_{V 1}$ becomes small enough, while remaining positive.

\section{RESULTS AND DISCUSSION}

\section{Experimental determination of chamber to condenser mass transfer resistance}

215 Table 1 summarizes the experimental values of the mass transfer resistance of chamber to

216 condenser pathway measured for various process conditions.

217 The effective mass transfer resistance appeared to increase when increasing chamber pressure, 218 decreasing shelf temperature and decreasing sublimation area. The mass transfer resistance 219 was thus inversely correlated with the sublimation flux. Increasing the sublimation rate 
resulted in an apparent decrease of the effective mass transfer resistance of the chamber to condenser pathway. These observed variations support the idea that the mass transfer resistance is only an effective model parameter and a different perspective is needed to get a more physically meaningful description of the transfer phenomena. This is further discussed in the next sections.

Prediction of partial vapor pressure in the chamber by the two modeling approaches: resistance vs. binary gas transport

The predictions of the previously developed freeze-drying model, ${ }^{[9]}$ adapted for bacterial suspension conditioned in trays, were compared to experimental measurements acquired in freeze-drying experiments performed as described in the "Materials and methods" section. Two versions of the model were tested, one based on a mass transfer resistance between the chamber and the condenser (Eq. 1) and the other based on the binary gas transport assumption (Eq. 16). Details of the existing model ${ }^{[9]}$ adaptation to the new freeze-dryer, container and product, as well as implementation details of the new chamber-to-condenser mass transport model based on Eq. 16 are given in the Appendix. The model parameters (notably $k_{m}$ and $\beta$ ) were determined by fitting the models to some of the experimental data obtained in bacterial suspension experiments (Appendix and Table 2)

An example of the predictions of the two versions of the model are shown in Figure 1, for two experiments performed at $0^{\circ} \mathrm{C}$ shelf temperature $/ 60 \mathrm{~Pa}$ chamber pressure and $25^{\circ} \mathrm{C} / 20 \mathrm{~Pa}$, respectively. These are validation experiments not used for model parameter identification. Dotted lines represent calculations based on the mass transfer resistance model and solid lines correspond to the binary gas transport model.

242 The experiment at $0^{\circ} \mathrm{C} / 60 \mathrm{~Pa}$ (Figure 1, left panels) illustrates a situation where the prediction 243 of the primary drying termination differs by about 2 hours between the considered models. 244 The end of the primary drying was arbitrarily defined here as the moment when the sublimation flux (Figure 1C) decreased below 5\% of its maximum value. The resistance model predicts the end of the primary drying at about $11 \mathrm{~h}$, in agreement with measured product temperature approaching the shelf temperature (Figure 1A), while the binary gas model predicts the end at bout $13 \mathrm{~h}$, in agreement with the decrease of vapor pressure in the chamber (Figure 1B). Note that product temperature measurement is a local one, potentially disturbed by the presence of the probe, while partial vapor pressure measurement is a global one, representative of the whole product in the freeze-dryer. Vapor pressure should thus be 
252 preferred to assess the end of the primary drying. ${ }^{[14]}$ It is also non intrusive and usually more 253 conservative, minimizing the risk of premature temperature increase and product damage, if 254 some ice was still present when starting the secondary drying step.

255 The experiment at $25^{\circ} \mathrm{C} / 20 \mathrm{~Pa}$ (Figure 1, right panels) illustrates a situation where both models 256 predict the same end point of the primary drying $(11 \mathrm{~h})$, but the vapor pressure predicted by 257 the resistance model is completely in error. Compared to the previously described experiment $258\left(0^{\circ} \mathrm{C} / 60 \mathrm{~Pa}\right)$, in this case the heat transfer resistance from the shelf to the product is higher due 259 to lower chamber pressure (lower contribution of the gas conduction), but this is nearly 260 compensated by a higher shelf temperature, leading to a similar heat flux. The net result is a 261 similar primary drying time and sublimation flux (Figure 1C) for both experimental conditions. As expected from Eq. 1, a similar sublimation flux implies a similar vapor pressure calculated with the resistance model, around 50Pa in this case (Figure 1B), but this value is 2.5 times higher than the total pressure, which is obviously incorrect. In contrast, the binary gas model based on Eq. 16 consistently predicts a vapor pressure close to, but slightly less than the total one, as physically expected.

Both these examples suggest that the binary gas transport model should be preferred to the resistance model. Similar trends were observed in all performed experiments with bacterial suspensions (data not shown). The properties of the proposed binary gas transport model are further examined in the following sections.

Effective mass transfer resistance of the chamber to condenser pathway

273 Since Eq. 1 and Eq. 14 are two different ways of expressing the same vapor flux based on 274 different physical assumptions, these equations can be used to define an effective mass 275 transfer resistance of chamber to condenser pathway as:

$276 \quad$ Eq. 18

$$
r_{m}=\frac{1}{k_{m}}=\frac{l_{e f f} R T\left(P_{V 1}-P_{V 2}\right)}{A M_{V} P_{t} D_{V N} \ln \frac{P_{t}-P_{V 2}}{P_{t}-P_{V 1}}}=\beta T \frac{P_{V 1}-P_{V 2}}{\ln \frac{P_{t}-P_{V 2}}{P_{t}-P_{V 1}}}
$$

277 It readily appears from Eq. 18 that this resistance is not constant but is an effective model 278 coefficient that depends on the actual values of the total and vapor pressure.

279 The effective mass transfer resistance given by Eq. 18 is plotted in Figure 2 (solid line) as a 280 function of the vapor pressure near the product $\left(P_{V 1}\right)$, for two different total pressures $\left(P_{t}=20\right.$ 
and $60 \mathrm{~Pa}$ ) used in our experiments. The vapor pressure near the condenser was fixed to a low value $P_{V 2}=0.055 \mathrm{~Pa}$, corresponding to a typical condenser temperature of $-80^{\circ} \mathrm{C}$. For comparison, the value of $r_{m}$ determined for the mass transfer resistance model in the same conditions is also given in Figure 2 (dotted line).

Firstly, Figure 2 indicates that the effective mass transfer resistance strongly increases with the total pressure. This was expected from the experimental data in Table 1 and confirms the usual practice of performing freeze-drying at low pressure to improve mass transfer.

Secondly, the effective mass transfer resistance predicted by the binary gas model approaches zero when the vapor pressure in the chamber approaches the total pressure. This was expected from the mathematical analysis of Eq. 18 and is consistent with the fact that partial vapor pressure in the chamber cannot exceed the total one, whatever the sublimation flux. Note that this is not the case with a constant mass transfer resistance, when the vapor pressure in the chamber can formally exceed the total pressure for a sufficiently high sublimation flux in Eq. 1 .

Finally, Figure 2 shows that the value of the mass transfer resistance determined using the resistance model based on Eq. 1 is situated between the bounds given by Eq. 18, as expected. The effective resistance given by the binary gas transport model is close to this value for vapor pressures very close to the total pressure. This means that the vapor pressure calculated by the binary gas model for the primary drying is most of the time very close to the total pressure, as observed in Figure 1 and well known from freeze-drying practice. This is further illustrated in the following section.

\section{Sublimation flux and predicted vapor pressure in the chamber}

In usual freeze-drying conditions the sublimation mass flux is the result of several process parameters (Table 1), such as total chamber pressure (that changes both heat and mass transfer), shelf temperature and sublimation interface area, etc. For the mass transfer resistance model given by Eq. 1, the predicted vapor pressure in the freeze-drying chamber varies linearly with the mass flux (dotted line in Figure 3) and can, as already mentioned, exceed the total pressure, for example in the case of a sufficiently high shelf temperature (Figure 1, right panels). In contrast, the vapor pressure predicted by the gas diffusion model given by Eq. 16 asymptotically tends towards the total pressure for high sublimation mass fluxes, which is physically consistent (solid lines in Figure 3). This also corroborates the well 
312 known fact that gas composition in the freeze-drying chamber is dominated by vapor during 313 most of the primary drying stage, when sublimation fluxes are high (approaching $2 \times 10^{-5} \mathrm{~kg} \mathrm{~s}^{-1}$

314 in the considered experimental setting).

315 Sublimation flux and effective mass transfer resistance of the chamber to condenser pathway

316 Considering the effect of the sublimation mass flux in the binary gas transport model gives a 317 common framework to understand the apparent variations of the effective mass transfer 318 resistances observed in Table 1 for different shelf temperatures and sublimation interface 319 areas. Increasing both these variables increases the sublimation flux and this, in turn, causes 320 an apparent reduction of the effective mass transfer resistance (Figure 4). For sublimation 321 fluxes approaching $2 \times 10^{-5} \mathrm{~kg} \mathrm{~s}^{-1}$, representative of the primary drying in the considered 322 experiments (Figure 1), the mass transfer resistance determined for the resistance model is intermediate between those calculated with the binary gas model for 20 and $60 \mathrm{~Pa}$ total pressure. This reflects the compromise that the model fitting procedure finds to accommodate experiments performed at both these pressures, but the achieved compromise underestimates the vapor pressure at $60 \mathrm{~Pa}$ and overestimates it at $20 \mathrm{~Pa}$, as already shown in Figure 1.

\section{The binary gas transport model needs a unique constant parameter}

328 As an additional difference between the two models, note that in the mass transfer resistance 329 model the value of the resistance between the chamber and the condenser pathway is only an 330 effective model parameter that appears to be a function of several process variables (Table 1): total pressure, shelf temperature and product sublimation area. Accounting for this would require varying the resistance in a tricky and ad-hoc manner. Considering a constant value of the mass transfer resistance $\left(r_{m}=2.78 \times 10^{6} \mathrm{~Pa} \mathrm{~s} \mathrm{~kg}^{-1}\right.$ in our case) leads to poor predictions and

334 inconsistencies, such as calculated partial vapor pressure in the chamber exceeding the total 335 one (Figure 1 and Figure 3). On the contrary, binary gas diffusion theory states that the 336 product $P_{t} D_{V N}$ is constant and therefore in the binary gas transport model the analogous 337 parameter $\beta$, given by Eq. 15, is constant. All solid plots in Figures 1-4 were obtained with 338 the same value of $\beta=2.66 \times 10^{3} \mathrm{~s} \mathrm{~kg}^{-1} \mathrm{~K}^{-1}$.

339 In-process mass flux estimation and detection of the primary drying termination

340 Eq. 16 could be used in principle for obtaining vapor flow rate estimations based on total and 341 partial pressure measurements, and thus act as an in-process mass flow meter. In practice, 
342 however, estimations of "high" vapor flow rates (i.e. when the partial vapor pressure

343 approaches the total one) are expected to be inaccurate due to the vapor saturation of the 344 chamber illustrated in Figure 3: a wide range of sublimation fluxes corresponds to almost 345 identical partial vapor pressures, very close to the total chamber pressure. For example, with 346 the considered values of the parameters (Appendix) at a total pressure of 60Pa, a vapor 347 pressure of $59.99 \mathrm{~Pa}$ corresponds to a sublimation flux of $1.14 \times 10^{-5} \mathrm{~kg} \mathrm{~s}^{-1}$, while a vapor 348 pressure of $58.99 \mathrm{~Pa}$ corresponds to a sublimation flux of $0.53 \times 10^{-5} \mathrm{~kg} \mathrm{~s}^{-1}$. In other words, an 349 uncertainty of only $1 \mathrm{~Pa}$ in the measurement of the vapor pressure would induce a factor 2 350 error on the flux value, which is clearly inappropriate for practical use.

351 On the contrary, Figure 3 suggests that the estimation of "low" vapor fluxes (i.e. when the 352 partial vapor pressure is well below the total one) based on pressure measurements could be quite accurate. For example, vapor pressures of 30 and $29 \mathrm{~Pa}$ correspond to vapor fluxes of $3540.091 \times 10^{-5} \mathrm{~kg} \mathrm{~s}^{-1}$ and $0.086 \times 10^{-5} \mathrm{~kg} \mathrm{~s}^{-1}$ respectively; a measurement uncertainty of $1 \mathrm{~Pa}$ would 355 induce only about $5 \%$ error on the vapor flux.

356 Above considerations suggest that the proposed model is appropriate for a safe detection of 357 the primary drying termination because a decrease of the vapor pressure well below the total 358 one indicates a strong decrease of the sublimation flux. Continuing the above numerical examples, a vapor pressure in the chamber decreasing to the half of the total pressure corresponds to a factor 10 reduction of the sublimation flux. Of course, exact significance of "high" and "low" mass fluxes and the relevant decrease of vapor pressure depend on numerical values grouped in the parameter $\beta$ defined by Eq. 15, and also involved in Eq. 16 .

363 Finally, note that the proposed in-process flow estimation method based on total and partial 364 pressure measurements in the chamber is complementary to the method described by Patel et 365 al. ${ }^{[31]}$, based on differential pressure measurement between the chamber and the condenser. 366 Indeed, the former works well for low sublimation fluxes while the latter is expected to be 367 more accurate when the sublimation flux, and hence the measured pressure difference, are 368 large.

370 Results presented in this paper suggest that using one-dimensional mass transfer theory in 371 binary gas mixtures to describe vapor transfer between the freeze-drying chamber and the 372 condenser should be preferred to the mass transfer resistance approach. Advantages of the 
373 binary gas transport model include: (i) prediction of the vapor pressure in the freeze-drying 374 chamber closer to the experimental one, leading to more reliable prediction of the end of the 375 primary drying; (ii) calculated values of the vapor pressure physically consistent with the total 376 pressure, whatever the sublimation vapor flux; (iii) need to determine a single model 377 parameter for a given freeze-dryer geometry, independent on the operating conditions (total 378 pressure, shelf temperature, ice sublimation area).

379 The main drawback of the mass diffusion model is the non-linear dependence between the 380 vapor flux and vapor pressure, which can somewhat complicate model simulations. Solution 381 of non-linear differential and algebraic equation sets is already part of most freeze-drying 382 models, however, and the additional difficulty introduced by the diffusion model is expected 383 to be minor, as confirmed by the authors' experience.

384 The assumption of one-dimensional mass transfer between the freeze-drying chamber and the 385 condenser could be questioned in the future, especially for freeze-dryers with the condenser 386 situated in the freeze-drying chamber. The challenge would be to end up with a reasonably 387 simple closed-form relationship between mass flux and pressure, in order to maintain the 388 overall model minimalism and short simulation time.

\section{NOMENCLATURE}

$\begin{array}{llll}390 & c & \text { molar concentration } & \mathrm{kmol} \mathrm{m}^{-3} \\ 391 & f & \text { mass flux density } & \mathrm{kg} \mathrm{s}^{-1} \mathrm{~m}^{-2} \\ 392 & k & \text { mass transfer coefficient } & \mathrm{kg} \mathrm{s}^{-1} \mathrm{~Pa}^{-1} \\ 393 & l & \text { diffusion length } & \mathrm{m} \\ 394 & r & \text { mass transfer resistance } & \mathrm{Pa} \mathrm{s} \mathrm{kg} \\ 395 & x & \text { molar fraction } & \mathrm{kmol} \mathrm{kmol}^{-1} \\ 396 & A & \text { diffusion cross-section area } & \mathrm{m}^{2} \\ 397 & D & \text { mutual diffusion coefficient } & \mathrm{m}^{2} \mathrm{~s}^{-1} \\ 398 & F & \text { mass flux } & \mathrm{kg} \mathrm{s}^{-1} \\ 399 & K_{n} & \text { Knudsen number } & - \\ 400 & M & \text { molar mass } & \mathrm{kg} \mathrm{kmol}^{-1}\end{array}$




$\begin{array}{llll}401 & N & \text { molar flux density } & \mathrm{kmol} \mathrm{s}^{-1} \mathrm{~m}^{-2} \\ 402 & P & \text { pressure } & \mathrm{Pa} \\ 403 & R & \text { ideal gas constant } & \mathrm{J} \mathrm{kmol}^{-1} \mathrm{~K}^{-1} \\ 404 & T & \text { absolute temperature } & \mathrm{K} \\ 405 & \text { Greek letters } & \\ 406 & \alpha & \text { heat conductivity ratio } & - \\ 407 & \beta & \text { mass transfer parameter } & \mathrm{s} \mathrm{kg}^{-1} \mathrm{~K}^{-1} \\ 408 & \lambda & \text { heat conductivity } & \mathrm{Wm}^{-1} \mathrm{~K}^{-1}\end{array}$

409 Subscripts

4101 freeze-drying chamber, near product

4112 condenser

4123 ice sublimation front

4134 product top

414 eff effective

$415 m$ mass

$416 t$ total

$417 N$ inert gas, nitrogen

$418 \quad V \quad$ solvent vapor, water

419 Superscript

$420 \quad P \quad$ measured by Pirani gauge

423 The research leading to these results has received funding from the European Community's 424 Seventh Framework Programme (FP7/2007-2013) under grant agreement CAFE $\mathrm{n}^{\circ} \mathrm{KBBE}-$ 425212754. 
The binary gas transport equation proposed in this paper (Eq. 16) describes the mass flux between the freeze-drying chamber and the condenser, in replacement of the more classical equation involving a mass transfer resistance or a mass transfer coefficient (Eq. 1). Both equations were tested in conjunction with an existing freeze-drying model, described in full detail previously. ${ }^{[9]}$

434 In a first step, the parameters of the existing model ${ }^{[9]}$ based on Eq. 1 were re-estimated to account for a different freeze-dryer (LyoBeta special freeze-dryer from Telstar, Terrassa, Spain, instead of SMH15 freeze dryer from Usifroid, Maurepas, France), a different container (metallic tray instead of glass vial) and a different product (lactic acid bacterial suspensions in sucrose medium instead of polyvinylpyrrolidone). Parameters related to the sorption isotherm and to the glass transition of the product were determined with the methodology described previously. ${ }^{[25]}$ Parameters related to the heat and mass transfer in the freeze-dryer and in the product were estimated by fitting the product temperature and vapor pressure predicted by the model to experimental measurements. Four experiments were used simultaneously for model parameter estimation, performed in the following combinations of shelf temperature and total chamber pressure: $-20^{\circ} \mathrm{C} / 20 \mathrm{~Pa},-20^{\circ} \mathrm{C} / 60 \mathrm{~Pa}, 25^{\circ} \mathrm{C} / 20 \mathrm{~Pa}$ and $25^{\circ} \mathrm{C} / 60 \mathrm{~Pa}$. A genetic optimization algorithm (Global Optimization Toolbox for Matlab, Natick, MA) was used for parameter identification. Since the considered optimization algorithm is stochastic, the parameter set with the best fit from 8 independent optimization runs was selected. Most optimization runs consistently converged to similar sets of parameters, usually within $\pm 10 \%$. Model parameters used in the present study are listed in Table 2.

450 In a second step, the original mass transfer equation between the chamber and the condenser 451 (Eq. 1) was replaced by the newly proposed one (Eq. 16) and the parameter estimation procedure was repeated using the same data and the same algorithm. The estimated parameter values are also given in Table 2. As expected, the estimated values of the parameters are similar between the two models, with the exception of the parameter describing mass transfer between the freeze-drying chamber and the condenser $\left(k_{m}\right.$ for the resistance model and $\beta$ for the binary gas transport model), which have different physical meanings.

457 Since the newly introduced equation is nonlinear and the vapor pressure in the chamber is 458 unknown a priori, the sublimation flux cannot be determined explicitly as in the resistance 
459 version of the model. ${ }^{[9]}$ The vapor pressure in the chamber $\left(P_{V 1}\right)$ was considered as an 460 additional state variable and the corresponding mass balance equation in the freeze-drying 461 chamber was added to the existing set of differential equations:

462 Eq. 19

$$
\frac{M_{V} V_{1}}{R T} \cdot \frac{d P_{V 1}}{d t}=F_{V 31}-F_{V}
$$

463 Here $V_{1}$ is the freeze-drying chamber volume, $F_{V}$ is the chamber to condenser vapor flux 464 given by Eq. 16 and $F_{V 31}$ is the sublimation vapor flux between the ice sublimation front 465 (location 3) and the freeze-drying chamber (location 1), given by:

466 Eq. 20

$$
F_{V 31}=\frac{1}{\frac{1}{k_{m 34}}+\frac{1}{k_{m 41}}}\left(P_{V 3}-P_{V 1}\right)
$$

467 where $k_{m 34}$ and $k_{m 41}$ are the mass transfer coefficients between the sublimation front and the 468 product top (location 4), and between the product top and the chamber, respectively. Thus, 469 both mass fluxes involved in Eq. 19 can be written explicitly in terms of known (fixed or $470 \quad$ state) variables $\left(P_{V 1}, P_{V 2}\right.$, and $\left.P_{V 3}\right)$.

471 Note that in the original freeze-drying model vapor accumulation in the freeze-drying 472 chamber was neglected, based on a time scale analysis. ${ }^{[9]}$ This is formally equivalent to 473 setting the chamber volume $V_{1} \approx 0$ in Eq. 19, which would thus become an algebraic instead 474 of a differential equation. This version of the model was also tested but not retained, due to 475 occasional failures in solving the equation set during parameter identification. Observed 476 difficulties are likely to be related to the specific differential-algebraic equations (DAE) 477 solver available in Matlab (ode15s) which had numerical problems with some sets of 478 parameters tested by the optimisation algorithm. 
1. Tang, X.; Pikal, M.J. Design of freeze-drying processes for pharmaceuticals: practical advice. Pharmaceutical Research, 2004, 21(2), 191-200.

2. Sadikoglu, H.; Ozdemir, M.; Seker, M. Freeze-drying of pharmaceutical products: Research and development needs. Drying Technology, 2006, 24(7), 849-861.

487

3. Sadikoglu, H.; Liapis, A. Mathematical modelling of the primary and secondary drying stages of bulk solution freeze-drying in trays: parameter estimation and model discrimination by comparison of theoretical results with experimental data. Drying Technology, 1997, 15(3\&4), 791-810.

4. Sadikoglu, H.; Liapis, A. I.; Crosser, O. K. Optimal control of the primary and secondary drying stages of bulk solution freeze drying in trays. Drying Technology, 1998, 16(3-5), 399-431.

5. Sadikoglu, H.; Ozdemir, M.; Seker, M. Optimal control of the primary drying stage of freeze drying of solutions in vials using variational calculus. Drying Technology, 2003, 21(7), 1307-1331.

6. Gan, K. H.; Bruttini, R.; Crosser, O. K.; Liapis, A. I. Heating policies during the primary and secondary drying stages of the lyophilization process in vials: effects of the arrangement of vials in clusters of square and hexagonal arrays on trays. Drying Technology, 2004, 22(7), 1539-1575.

7. Chouvenc, P.; Vessot, S.; Andrieu, J.; Vacus, P. Optimization of the freeze-drying cycle: a new model for pressure rise analysis. Drying Technology, 2004, 22(7), 1577-1601.

8. Boss, E. A.; Filho, R. M.; de Toledo, E. C. V. Freeze drying process: real time model and optimization. Chemical Engineering and Processing, 12 2004, 43(12), 1475-1485.

9. Trelea, I. C.; Passot, S.; Fonseca, F.; Marin, M. An interactive tool for freeze-drying cycle optimisation including quality criteria. Drying Technology, 2007, 25, 741-751.

10. Velardi, S. A. and Barresi, A. A. Development of simplified models for the freezedrying process and investigation of the optimal operating conditions. Chemical Engineering Research \& Design, 2008, 86(A1), 9-22. 
510 11. Pisano, R.; Fissore, D.; Velardi, S. A.; Barresi, A. A. In-line optimization and control 511 of an industrial freezedrying process for pharmaceuticals. Journal of Pharmaceutical $512 \quad$ Sciences, 2010, 99(11), 4691-4709.

513 12. Antelo, L. T.; Passot, S.; Fonseca, F.; Trelea, I. C.; Alonso, A. A. Toward optimal 514 operation conditions of freeze-drying processes via a multilevel approach. Drying 515 Technology, 2012, 30(13), 1432-1448.

516 13. Gieseler, H.; Kessler, W. J.; Finson, M.; Davis, S. J.; Mulhall, P. A.; Bons, V.; Debo, 517 D. J.; Pikal, M. J. Evaluation of tunable diode laser absorption spectroscopy for in-process 518 water vapor mass flux measurements during freeze drying. Journal of Pharmaceutical $519 \quad$ Sciences, 2007, 96(7), 1776-1793.

520 14. Patel, S. M.; Doen, T.; Pikal, M. J. Determination of end point of primary drying in 521 522 freeze-drying process control. AAPS Pharmaceutical Science and Technology, 2010, 11(1), 73-84.

15. Fissore, D.; Velardi, S. A.; Barresi, A. A. In-line control of a freeze-drying process in 524 vials. Drying Technology, 2008, 26(6), 685-694.

16. Pikal, M. Heat and mass transfer in low-pressure gases: applications to freeze-drying. 526 Drugs and the Pharmaceutical Sciences, 2000, 102, 611-686.

527 17. Alexeenko, A. A.; Ganguly, A.; Nail, S. L. Computational analysis of fluid dynamics 528 in pharmaceutical freeze-drying. Journal of Pharmaceutical Siences, 2009, 98(9), 3483$529 \quad 3494$.

530 18. Rasetto, V.; Marchisio, D. L.; Fissore, D.; Barresi, A. A. On the use of a dual-scale 531 model to improve understanding of a pharmaceutical freeze-drying process. 532 Pharmaceutical Technology, 2010, 99(10), 4337-4350.

533 19. Ganguly, A. and Alexeenko, A. A. Modeling and measurements of water-vapor flow 534 and icing at low pressures with application to pharmaceutical freeze-drying. International 535 Journal of Heat and Mass Transfer, 2012, 55, 5503-5513.

536 20. Petitti, M.; Barresi, A.; Marchisio, D. L. Cfd modelling of condensers for freeze537 drying processes. Sadhana-Academy Proceedings in Engineering Sciences, 2013, 38(6), 538 1219-1239. 
21. Mascarenhas, W. J.; Akay, H. U.; Pikal, M. J. A computational model for finite element analysis of the freeze-drying process. Computer Methods in Applied Mechanics and Engineering, 8/15 1997, 148(1-2), 105-124.

22. Sheehan, P. and Liapis, A. I. Modeling of the primary and secondary drying stages of the freeze drying of pharmaceutical products in vials: Numerical results obtained from the solution of a dynamic and spatially multi-dimensional lyophilization model for different operational policies. Biotechnology and Bioengineering, 1998, 60(6), 712-728.

23. Song, C. S.; Nam, J. H.; Kim, C. J.; Ro, S. T. A finite volume analysis of vacuum freeze drying processes of skim milk solution in trays and vials. Drying Technology, 2002, 20(2), 283-305.

24. Hottot, A.; Peczalski, R.; Vessot, S.; Andrieu, J. Freeze-drying of pharmaceutical proteins in vials: modeling of freezing and sublimation steps. Drying Technology, 2006, 24(5), 561-570.

25. Passot, S.; Cenard, S.; Douania, I.; Trelea, I. C.; Fonseca, F. Critical water activity and amorphous state for optimal preservation of lyophilized lactic acid bacteria. Food Chemistry, 2012, 132, 1699-1705.

26. Jennings, T. Lyophilization: Introduction and basic principles. Interpharm/CRC: Boca Raton, 1999.

27. George, J. P. and Datta, A. K. Development and validation of heat and mass transfer models for freeze-drying of vegetable slices. Journal of Food Engineering, 3 2002, 52(1), 89-93.

28. Chouvenc, P.; Vessot, S.; Andrieu, J.; Vacus, P. Optimization of pharmaceuticals freeze-drying cycles: characterization of annealing effects by the pressure rise analysis method. In Drying 2004 - Proceedings of the 14th International Drying Symposium (IDS 2004), São Paulo, Brazil, August 22-25, 2004; 359-365.

29. Hottot, A.; Vessot, S.; Andrieu, J. Determination of mass and heat transfer parameters during freeze-drying cycles of pharmaceutical products. PDA Journal of Pharmaceutical Science and Technology, 2005, 59(2), 138-153.

30. Bird, R.; Stewart, W.; Linghtfoot, E. Transport phenomena. Wiley: New York, 1960. 
568 31. Patel, S. M.; Chaudhuri, S.; Pikal, M. J. Choked flow and importance of Mach I in 569 freeze-drying process design. Chemical Engineering Science, 2010, 65, 5716-5727. 
$572 \quad$ Figure captions

573

574 Figure 1. Comparison between experimental measurements and simulations with the binary gas transport and resistance models, for two experiments with lactic acid bacteria suspensions (left panel $0^{\circ} \mathrm{C} / 60 \mathrm{~Pa}$, right panel $25^{\circ} \mathrm{C} / 20 \mathrm{~Pa}$ ). (A): Shelf and product temperatures, (B): Total and vapour pressures, (C): Sublimation fluxes. Bold: shelf temperature and total pressure, symbols: measurements, solid: binary gas model, dotted: resistance model, vertical line: end of primary drying.

Figure 2. Variation of the effective mass transfer resistance with the vapor and total pressure. Numeric values are for lactic acid bacteria suspension. Solid: binary gas model, bold: total pressure $60 \mathrm{~Pa}$, thin: total pressure $20 \mathrm{~Pa}$, dotted: resistance model.

Figure 3. Predicted vapor pressure as a function of the sublimation mass flux. Numeric values are for lactic acid bacteria suspension. Solid: binary gas transport model, bold: total pressure $60 \mathrm{~Pa}$, thin: total pressure $20 \mathrm{~Pa}$, dotted: resistance model.

Figure 4. Apparent variation of the effective mass transfer resistance of the chamber to condenser pathway as a function of the sublimation mass flux. Numeric values are for lactic acid bacteria suspension. Solid: binary gas transport model, bold: total pressure 
596 Table 1. Chamber to condenser mass transfer resistance measured with pure ice.

597

\begin{tabular}{|l|l|l|l|}
\hline $\begin{array}{l}\text { Total } \\
\text { chamber } \\
\text { pressure } \\
(\mathrm{Pa})\end{array}$ & $\begin{array}{l}\text { Shelf } \\
\text { temperature } \\
\left({ }^{\circ} \mathrm{C}\right)\end{array}$ & $\begin{array}{l}\text { Sublimation } \\
\text { interface } \\
\text { area }\left(\mathrm{m}^{2}\right)\end{array}$ & $\begin{array}{l}\text { Chamber to } \\
\text { condenser } \\
\text { resistance } \\
\left(10^{6} \mathrm{~Pa} \mathrm{~s} / \mathrm{kg}\right)\end{array}$ \\
\hline 10 & & & 0.65 \\
20 & 0 & 0.074 & 1.29 \\
40 & 0 & 2.64 \\
60 & & & 3.72 \\
\hline & -15 & 0.074 & 4.31 \\
40 & 0 & & 2.64 \\
& 15 & 0.033 & 2.61 \\
\hline & & 0.074 & 1.29 \\
20 & 0 & 0.15 & 0.67 \\
\hline
\end{tabular}

598 
Table 2. Values of the freeze-drying model parameters

\begin{tabular}{|c|c|c|}
\hline \multicolumn{3}{|l|}{ Parameters defined by the experimental setup } \\
\hline Number of trays $(-)$ & \multicolumn{2}{|l|}{1} \\
\hline Sublimation area $\left(\mathrm{m}^{2}\right)$ & \multicolumn{2}{|l|}{0.0745} \\
\hline Mass of dry product (kg) & \multicolumn{2}{|l|}{0.0736} \\
\hline Mass of ice $(\mathrm{kg})$ & \multicolumn{2}{|l|}{0.3763} \\
\hline Product height in the tray $(\mathrm{m})$ & \multicolumn{2}{|l|}{0.0067} \\
\hline Volume of the freeze-drying chamber $\left(\mathrm{m}^{3}\right)$ & \multicolumn{2}{|l|}{0.202} \\
\hline \multicolumn{3}{|c|}{ Parameters specific for the product formulation, determined in separate experiments ${ }^{[25]}$} \\
\hline Sorption isotherm, wet basis $\left(\mathrm{kg} \mathrm{kg}^{-1}\right)$ & \multicolumn{2}{|c|}{$\frac{0.3190 a_{w}}{\left(1-0.9827 \mathrm{a}_{\mathrm{w}}\right)\left(1+6.3668 \mathrm{a}_{\mathrm{w}}\right)}$} \\
\hline Characteristic desorption time (s) & \multicolumn{2}{|c|}{10100} \\
\hline $\begin{array}{l}\text { Glass transition temperature of the frozen } \\
\text { product }\left({ }^{\circ} \mathrm{C}\right)\end{array}$ & \multicolumn{2}{|l|}{-36} \\
\hline $\begin{array}{l}\text { Glass transition temperature of the perfectly } \\
\text { dry product }\left({ }^{\circ} \mathrm{C}\right)\end{array}$ & \multicolumn{2}{|l|}{75.6} \\
\hline $\begin{array}{l}\text { Gordon-Taylor coefficient for glass transition } \\
\text { temperature }(-)\end{array}$ & \multicolumn{2}{|l|}{8.2} \\
\hline \multicolumn{3}{|c|}{ Heat and mass transfer parameters determined by model fitting } \\
\hline & $\begin{array}{l}\text { Mass transfer } \\
\text { resistance model }\end{array}$ & $\begin{array}{l}\text { Binary gas } \\
\text { transport model }\end{array}$ \\
\hline $\begin{array}{l}\text { Heat transfer coefficient by contact and } \\
\text { radiation, between shelf and product bottom } \\
\left(\mathrm{W} \mathrm{m}^{-2} \mathrm{~K}^{-1}\right)\end{array}$ & 6.74 & 7.29 \\
\hline $\begin{array}{l}\text { Heat transfer coefficient by gas conduction, } \\
\text { between shelf and product bottom }\left(\mathrm{W} \mathrm{m}^{-2} \mathrm{~K}^{-1}\right. \\
\left.\mathrm{Pa}^{-1}\right)\end{array}$ & 0.400 & 0.366 \\
\hline $\begin{array}{l}\text { Heat conductivity between sublimation front } \\
\text { and product top }\left(\mathrm{W} \mathrm{m}^{-1} \mathrm{~K}^{-1}\right)\end{array}$ & 0.0957 & 0.0996 \\
\hline $\begin{array}{l}\text { Heat transfer coefficient between product top } \\
\text { and chamber walls }\left(\mathrm{W} \mathrm{m}^{-2} \mathrm{~K}^{-1}\right)\end{array}$ & 3.79 & 3.03 \\
\hline $\begin{array}{l}\text { Vapor conductivity between sublimation front } \\
\text { and product top }\left(\mathrm{kg} \mathrm{s}^{-1} \mathrm{~m}^{-1} \mathrm{~Pa}^{-1}\right)\end{array}$ & $2.07 \times 10^{-8}$ & $1.98 \times 10^{-8}$ \\
\hline $\begin{array}{l}\text { Vapor transfer coefficient between product top } \\
\text { and chamber }\left(\mathrm{kg} \mathrm{s}^{-1} \mathrm{~m}^{-2} \mathrm{~Pa}^{-1}\right)\end{array}$ & $8.12 \times 10^{-5}$ & $3.68 \times 10^{-4}$ \\
\hline $\begin{array}{l}\text { Vapor transfer coefficient between chamber } \\
\text { and condenser } k_{m}\left(\mathrm{~kg} \mathrm{~s}^{-1} \mathrm{~Pa}^{-1}\right)\end{array}$ & $3.60 \times 10^{-7}$ & Not applicable \\
\hline $\begin{array}{l}\text { Vapor transfer parameter between chamber and } \\
\text { condenser } \beta\left(\mathrm{s} \mathrm{kg}^{-1} \mathrm{~K}^{-1}\right)\end{array}$ & Not applicable & $2.66 \times 10^{3}$ \\
\hline $\begin{array}{l}\text { Residual frozen layer thickness for gradual } \\
\text { transition between primary and secondary } \\
\text { drying }(\mathrm{m})\end{array}$ & 0.00173 & 0.00170 \\
\hline Effective chamber wall temperature $\left({ }^{\circ} \mathrm{C}\right)$ & 15.3 & 13.9 \\
\hline
\end{tabular}

601 Complete model equations and exact definitions of the model parameters are given in ref. ${ }^{[9]}$ 

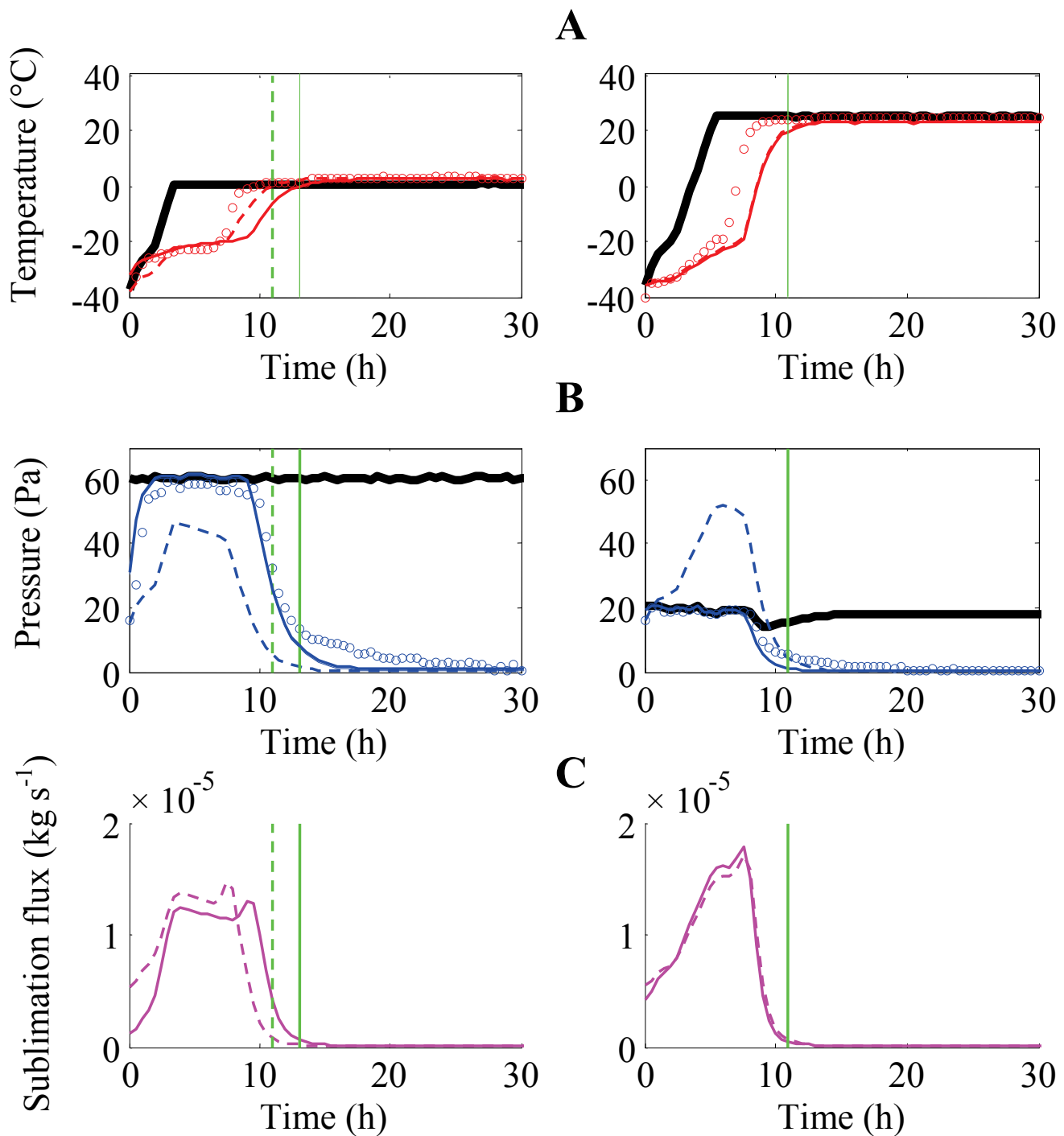

604

605

606 Figure 1. Comparison between experimental measurements and simulations with the binary 607 gas transport and resistance models, for two experiments with lactic acid bacteria suspensions 608 (left panel $0^{\circ} \mathrm{C} / 60 \mathrm{~Pa}$, right panel $25^{\circ} \mathrm{C} / 20 \mathrm{~Pa}$ ). (A): Shelf and product temperatures, (B): Total 609 and vapour pressures, (C): Sublimation fluxes. Bold: shelf temperature and total pressure, 610 symbols: measurements, solid: binary gas model, dotted: resistance model, vertical line: end 611 of primary drying. 


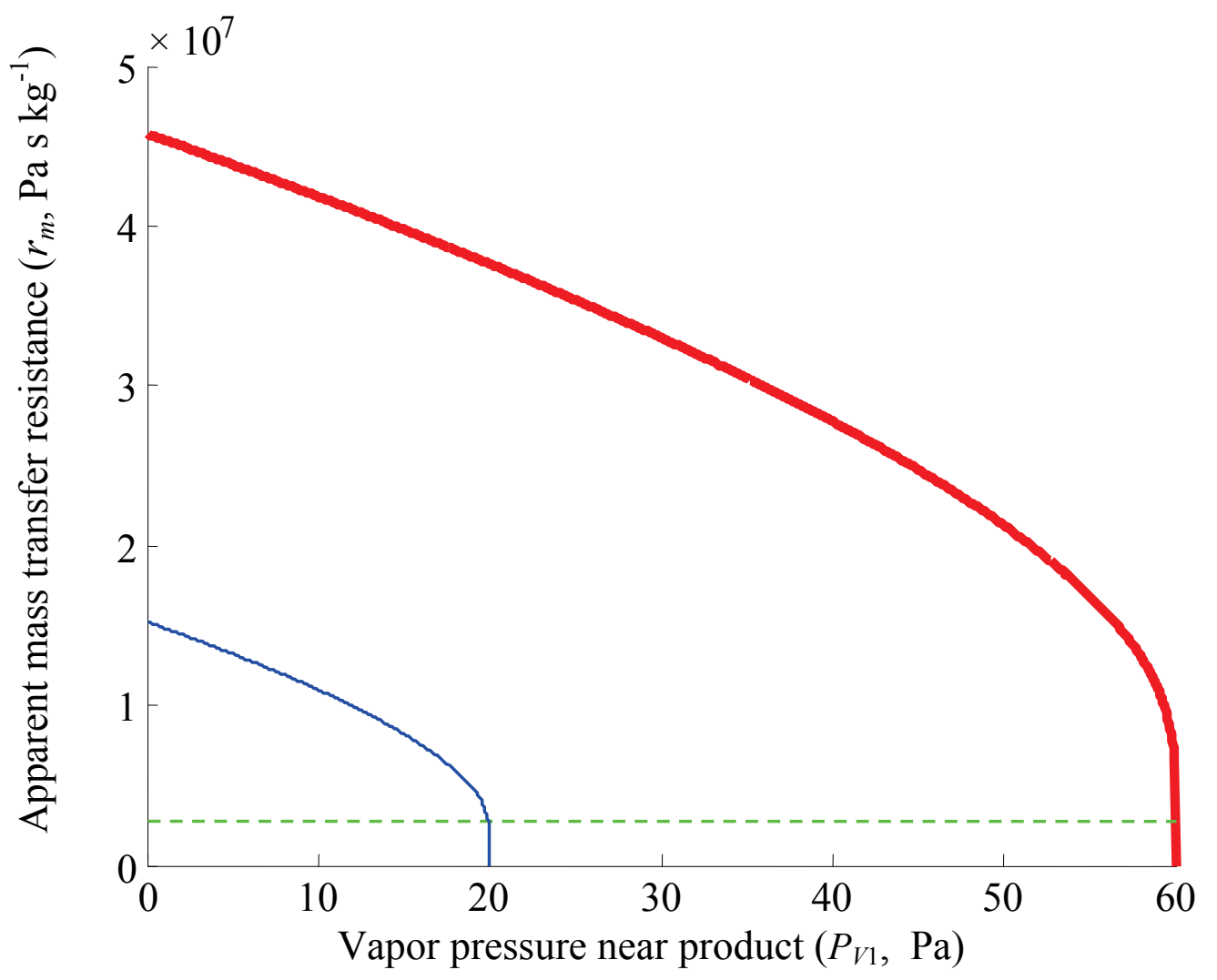

615

616

617 Figure 2. Variation of the effective mass transfer resistance with the vapor and total pressure.

618 Numeric values are for lactic acid bacteria suspension. Solid: binary gas model, bold: total 619 pressure $60 \mathrm{~Pa}$, thin: total pressure $20 \mathrm{~Pa}$, dotted: resistance model.

620 


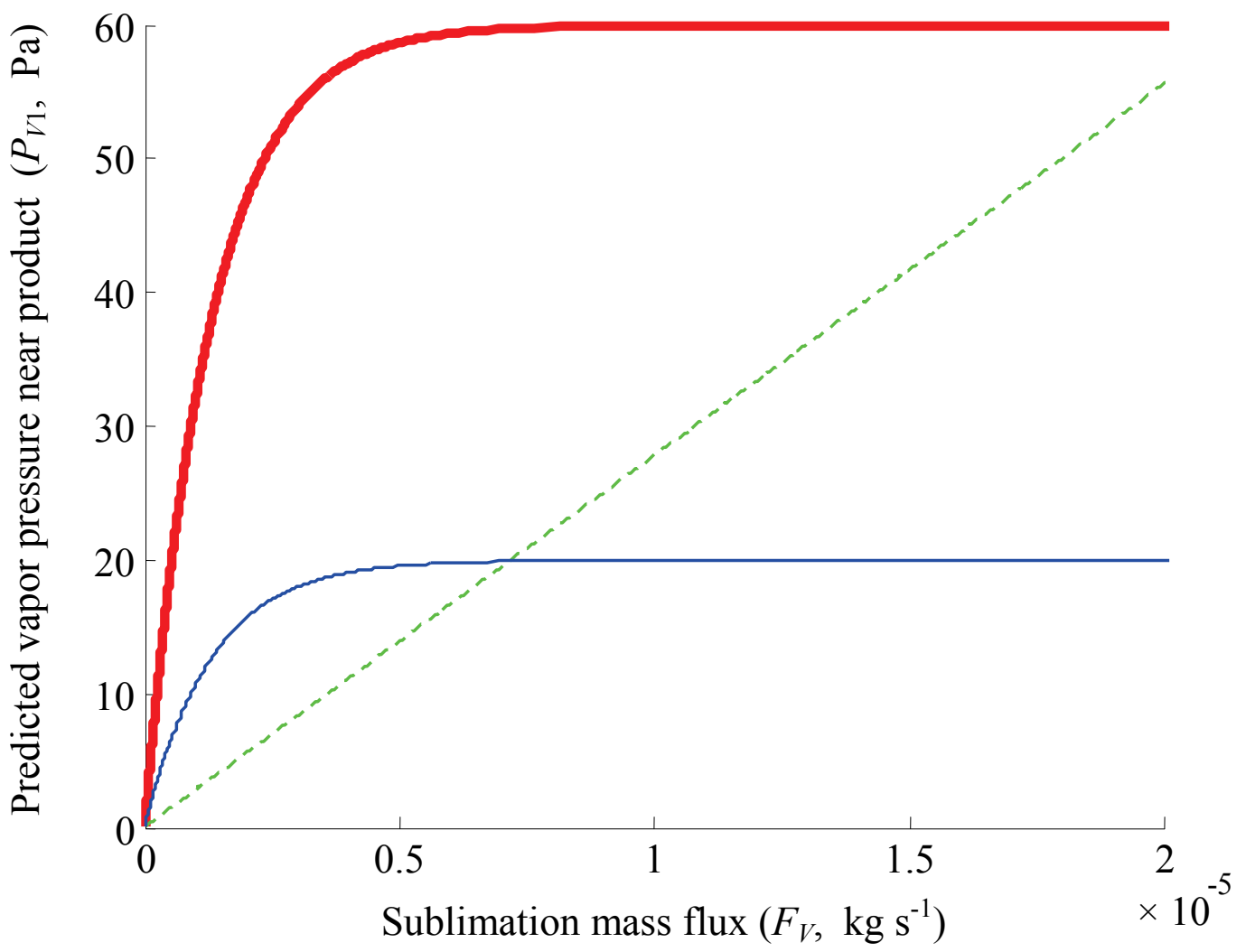

623

624

625 Figure 3. Predicted vapor pressure as a function of the sublimation mass flux. Numeric values 626 are for lactic acid bacteria suspension. Solid: binary gas transport model, bold: total pressure $62760 \mathrm{~Pa}$, thin: total pressure 20Pa, dotted: resistance model.

628

629 


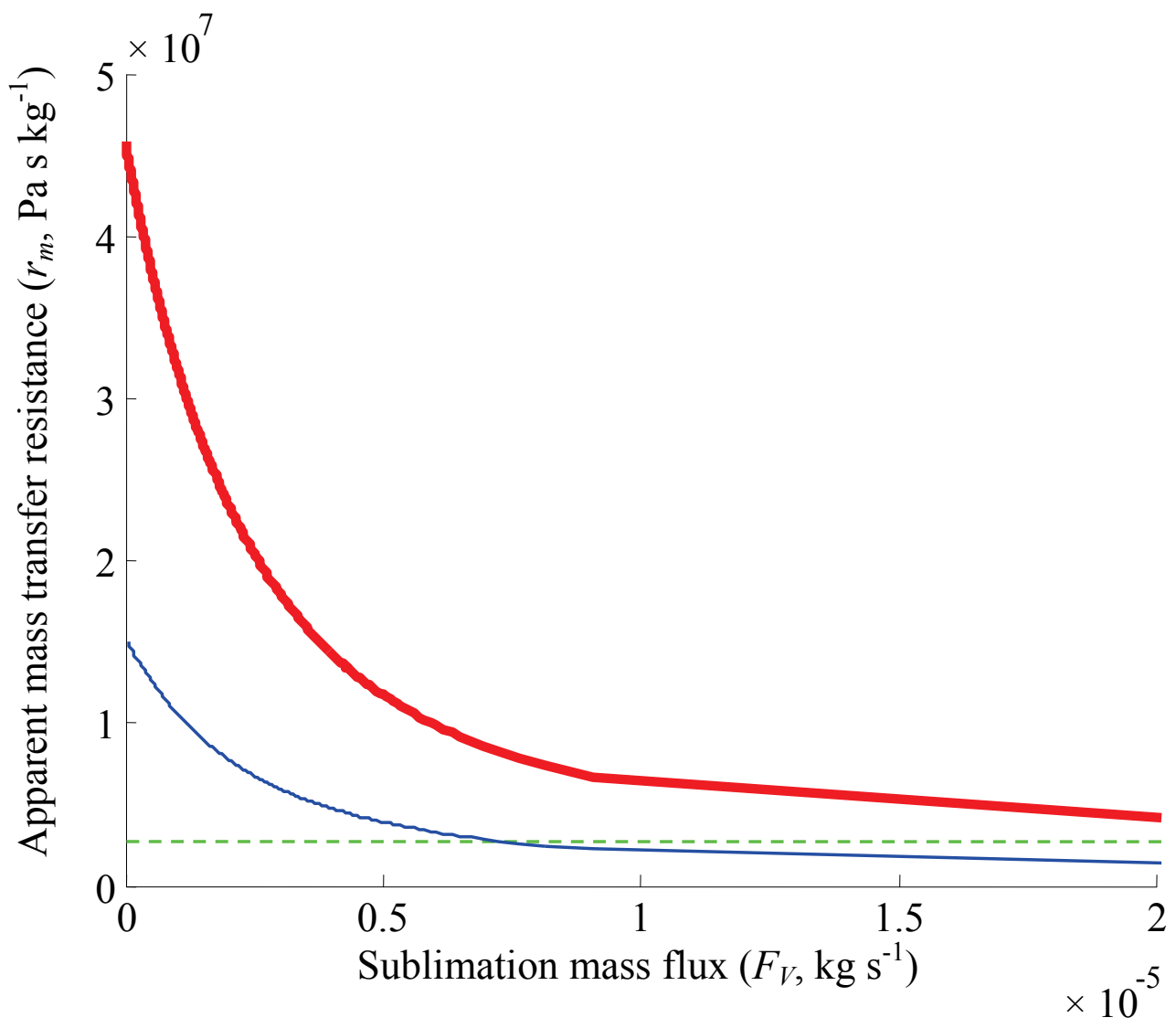

633

634 Figure 4. Apparent variation of the effective mass transfer resistance of the chamber to 635 condenser pathway as a function of the sublimation mass flux. Numeric values are for lactic 636 acid bacteria suspension. Solid: binary gas transport model, bold: total pressure 60Pa, thin: 637 total pressure 20Pa, dotted: resistance model.

638

639

640 